\title{
When Monkeys Fly: Making the Periodic Table Fun for Middle Schoolers
}

\section{Lynne Robinson}

Editor's Note: This is excerpted from an article that first appeared on the MaterialsTechnology@ TMS site at http://materialstechnology.tms.org/edu /article. aspx?article/D=2819.

Few realms are more mysterious than the middle school mind. Undaunted, Garry Warren, professor in the Department of Metallurgical and Materials Engineering at the University of Alabama, Tuscaloosa, launched a quest several years ago to captivate this notoriously fickle age group with the Periodic Table of Elements.

That's right, the Periodic Table of Elements, that elegant system that quite literally defines all of materials science. But despite its lofty stature (and the fact that TMS named its inception the top Materials Moment of all time), most pre-teens have difficulty appreciating its importance, particularly as they struggle to make sense of a seeming jumble of abbreviations, numbers, and concepts. Enter the University of Alabama's Periodic Table Game, an online arcade that uses flying monkeys and lovelorn electrons to make exploration of this venerable reference tool both un- derstandable and fun. Warren said that he and the other game creators wanted to take students beyond rote memorization to show them the relevance of the Periodic Table to everyday life. For this reason, clues to solving many of the puzzles focus on the role of elements in manufacturing, energy, and product development.

Warren first proposed the Periodic Table Game concept in 2003 as an adjunct activity to the university's Materials Research Science and Engineering Center (MRSEC), recently funded by the National Science Foundation (NSF). To fulfill the NSF's educational outreach requirements, the MRSEC had joined forces with the university's Integrated Science program, a Webbased middle-school science curriculum. Teachers involved with the Integrated Science program, as well as the MRSEC's Research Experience for Teachers (RET) summer program, were recruited to develop many of the game's questions and clues. With support fromTMS, the university purchased software to create a fanciful gaming world

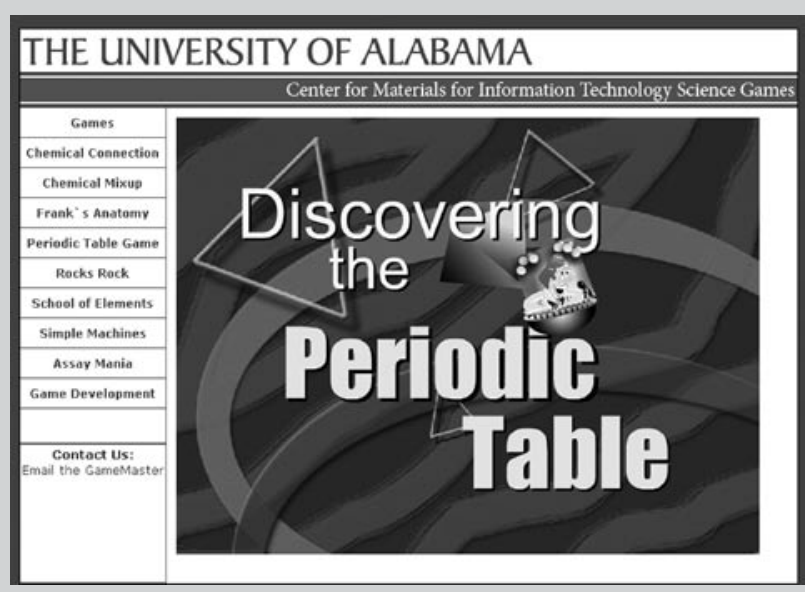

Figure 1: The Periodic Table Game home page. programmed by paid undergraduate honors students. Students participating in the university's Research Experience for Undergraduates (REU) program, as well as a number of faculty, also aided in the game's development.

As the roster of game creators grew, so did the breadth and complexity of the game. "I thought we would be finished in two to three years, but we kept adding games," Warren said. After more than five years of development, Martin G. Bakker, associate professor of Physical Chemistry, finally launched the Periodic Table Game on the university's Web site. In the last year and a half, the Periodic Table Game has garnered more than 15,000 hits. Warren said anecdotal evidence suggests that, when used formally in the classroom, the game has helped students improve their "elementary" knowledge.

The current version of the elemental arcade is organized within a "Periodic Pyramid," with the "Periodic Puzzler," a word game that tests basic knowledge of the elements, forming the base. The next level is "Monkey Mayhem,' where players are challenged to match an element-toted by a point-stealing monkey-to its correct position on the Periodic Table. The final game, "To Bond or Not to Bond," uses a Dating Game format to match an "Eligible Element" with one of three "Mystery Elements." Said Warren, "We devised this for middle school students, but my undergraduates thought some of those questions were pretty challenging."

The Periodic Table Game can be accessed at http://mint.ua.edu/games lgames.asp?id=periodic_table_game.

Lynne Robinson is a writer for Materials Technology@TMS. 